\title{
Factors influencing the rate of recycling: an analysis of Minnesota counties
}

\begin{abstract}
This study analyzes the effects of various recycling and waste management policy variables on recycling rate by utilizing county-level panel data from Minnesota covering the period 1996ï 2004. The policy variables examined include variable pricing for waste disposal, expenditure on recycling education, provision of curbside recycling services and drop-off centers, and enactment of recycling ordinances. Unlike previous studies, this study accounts for the cumulative effects of the expenditure variable on recycling rate and also investigates whether different recycling programs such as curbside and drop-off recycling act as complements or substitutes in increasing recycling rates. This study also examines the effect of income and demographic characteristics on recycling rate. After accounting for random effects and endogenous variables, the results indicate that variable pricing of waste disposal increases the rate of recycling. Other policy variables such as the enactment of recycling ordinances and cumulative expenditures on recycling education are also found to be effective measures to increase recycling rate.
\end{abstract}

Keyword: Recycling; Recycling expenditure; Recycling education; Municipal solid waste; Waste management 